\title{
Experiencia de talleres para niños y adolescentes víctimas directas de la dictadura militar argentina ${ }^{1}$
}

\author{
Psic. Cristina Solano ${ }^{2}$
}

Pensar sobre la relación entre la política de derechos humanos (en adelante DDHH) y el quehacer de los profesionales - no sólo de la psicología sino de casi todas las profesiones- no es una tarea sencilla ni lineal. Sobre todo si nos ocupamos de épocas en donde lo que está puesto en juego es la seguridad y hasta la vida.

En la década del '70 ante el avance de la represión y la creciente desaparición de miles de habitantes de nuestra ciudad y del país comenzaron a surgir los organismos de DDHH. Primero la Asamblea Permanente por los DDHH formada en diciembre de 1975; en la Liga Argentina por los Derechos del Hombre (creada en 1937) se comienzan a reunir en 1976 grupos de madres y familiares de las víctimas de la represión y en septiembre de 1976 se crea Familiares de Desaparecidos y Detenidos por Razones Políticas.

Al poco tiempo ellos mismos descubren que precisan ayuda psicológica. Padecían en forma particular y grupal diferentes síntomas debidos al sufrimiento que estaban viviendo. Y allá fuimos, pocos, muy pocos, no eran tiempos gloriosos y los psicólogos éramos un grupo bastante perseguido. De hecho sólo ser terapeutas de militantes podía costar mucho.

Bien, en esa tarea se comenzó a trabajar. Jóvenes recién recibidos con poca experiencia clínica y sin ningún tipo de supervisión pero dispuestos a colaborar con situaciones que hubiesen superado a otros más capacitados.

Esta tarea fue particular en muchos sentidos, entre otras cosas porque los mismos pacientes eran también los compañeros de militancia diaria, y esto porque la tarea era militante por sobre todas las cosas. Introducirse en la temática de los DDHH implicaba meterse en un compromiso fundamentalmente político e ideológico, al cual sumabas tu formación profesional.

A esto se agrega el hecho de incursionar en una forma de trabajo absolutamente novedosa, no sólo para nosotros sino para cualquier profesional psicólogo por estos lugares del mundo. Improvisamos, así comenzamos, improvisando: atendiendo consultas en los locales de militancia, interviniendo cuando surgía algún conflicto interno, atendiendo algunos pacientes en los consultorios privados, con el conocimiento mutuo que allí nos encontrábamos en terapia pero

\footnotetext{
${ }^{1}$ Ponencia Panel VII Jornadas Psicoanálisis, Salud y Políticas Públicas, organizadas por la Cátedra Libre Oscar Masotta - Octubre 2017.

${ }^{2}$ Psicóloga de organismos de Derechos Humanos (Madres de Plaza de Mayo Rosario. Abuelas de Plaza de Mayo CABA. Familiares de Detenidos Desaparecidos Rosario, Defensa del niño Internacional DNI; Codesed CABA, Asociacion Anahi, La Plata, Rosario. Coordinadora del àrea de Psicologìa del Taller Había un vez,Rosario, etc.).

Psicóloga e Investigadora de la salud de los veteranos de guerra de Malvinas a nivel nacional. Miembro de la Red de Psicología Nuestramericana . Sede central Venezuela.

Ex docente UBA y UNR.
} 
luego nos íbamos a ver en las marchas, en diferentes circunstancias, o yendo a buscar a un compañero en peligro, pero eso lo íbamos a tratar en análisis, o sea procurando sostener el encuadre en todas las aristas en que este se jugaba.

Así pasamos los peores años, nosotros solos en Rosario, sin contacto con terapeutas de otros lugares ni tampoco del propio. No es necesario aclarar que esa tarea era absolutamente gratuita.

Llegó el fin de la dictadura, y con ello otra etapa. Aún esperar con vida a los desaparecidos. Muchos creíamos que con la democracia iban a ser liberados, vana ilusión, sólo quedaron los presos reconocidos en las cárceles del país, la mayoría iban siendo liberados. Ahora había que intentar ayudar para tratar de reparar algo, habían sido lastimados en el cuerpo y en la psiquis.

En ese momento también pudimos ver que nos rodeaban una cantidad de personitas que en los años oscuros estaban entre nosotros, durmiendo en sillas, esperando, escuchando testimonios atroces, mudándose de casa en casa, marchando con los adultos, eran niños, hijos de los presos, de los desaparecidos, de los militantes a quienes no se les había podido prestar atención. Tantas eran las urgencias que no habíamos visto a los niños.

Era el momento de ocuparse de ellos. Y surge nuevamente la inventiva. Ya trabajábamos mancomunadamente con otros organismos del país y aparece la idea de comenzar a reunirnos con los chicos para realizar juntos las tareas que se nos ocurriesen entre todos.

El primer objetivo era brindarles un espacio propio. Ahora nos íbamos a reunir y trabajar con los chicos y para los chicos.

Era importante convocarlos muchas veces venciendo sus propias resistencias, ofreciendo un espacio de confianza, de crecimiento conjunto. Se trataba de niños que habían crecido ocultando sus nombres, mintiendo sus domicilios en las escuelas, muchos se habían criado lejos de sus padres, con familiares que culpaban a éstos del abandono y ellos habían mamado el rencor y la vergüenza de tener a los padres presos o desaparecidos, otros crecieron en la mentira o en el ocultamiento. Eran niños cuyos roles familiares habían tenido que cambiar, niños que habían nacido en medio de la tortura de sus madres, que habían estado presos ellos también, niños que venían del exilio, niños huérfanos, niños que buscaban a sus padres ausentes en cada hombre o mujer que veían parecidos a la imagen o las fotos que se conservaban de ellos. Esos niños marchaban como adultos por las calles con carteles colgados de sus cuellos pidiendo aparición con vida de sus papás.

No iba a ser fácil la tarea.

Uno de los grandes temores era crear otro gueto. Otro lugar donde ellos fueran diferentes y alejados del resto de los chicos. Se nos ocurrió como medida parcial, que pudieran invitar a los amigos que quisieran venir.

Otro de las advertencias más fuertes era que ninguno de nosotros se viese tentado a "bajar línea" política, reivindicando las posiciones políticas de sus padres o alguna otra posible.

Al mismo tiempo -y creo que esto era lo fundamental-hacerles dejar de sentir vergüenza de su historia. El discurso hegemónico durante la dictadura era que los militantes eran delincuentes, asesinos, terroristas, que debían ser delatados y perseguidos, y los niños se habían criado con eso. El planteo fue sostener que sus padres habían dado su libertad y su vida porque querían que todos viviéramos en un mundo mejor, que su lucha era una lucha justa y que lo habían hecho pensando en ellos, para dejarles un mundo más digno. 
También había que reflexionar acerca de qué podía pasar con el aprendizaje escolar en niños cuyos padres habían sido matados por pensar, de qué modo esto iba a marcarlos.

Con algunas de estas premisas empezamos a trabajar. Los llamamos talleres y funcionaron en Rosario, Buenos Aires, Córdoba, Capital Federal y La Plata.

El problema era dónde, en qué lugar lo podíamos hacer. Para esto usamos los lugares más increíbles, en ese momento todavía no era fácil ni seguro cobijarnos, lo nuestro fue un deambular constante y esto duró más de 10 años. Nuestro agradecimiento eterno a quienes nos alojaron.

Nos dividíamos en talleres con cada temática específica. A nuestra propuesta se unieron profesores de educación física, titiriteros, actores, pintores, maestros jardineros, maestros, psicólogos. Los chicos elegían qué tareas querían realizar, pero se tendía a que cumplieran un cometido, un objetivo.

También organizábamos campamentos en algún lugar que nos prestaban. Todo tenía que venir por solidaridad, no contábamos con recursos económicos, sólo lo de Rada Banner, organismo sueco de derechos humanos, que alcanzaba para lo mínimo.

Hubo una experiencia muy significativa que marcó a los chicos fuertemente, conseguimos unas vacaciones gratis en los balnearios de Chapadmalal. Fuimos los talleres Julio Cortázar de Córdoba, de La Amistad de La Plata, el de Buenos Aires, y el Había una vez de Rosario. La mayoría de los chicos nunca había visto el mar, disfrutaron muchísimo. El problema fue al regreso y debíamos separarnos. Esto fue desgarrador, tomamos un tren y nos íbamos separando por etapas, primero llegamos a La Plata y luego de una visita a su taller y a la ciudad debíamos seguir a Rosario y luego continuarían los cordobeses. Realmente no habíamos previsto lo que luego sucedió, los chicos se abrazaban y no querían separarse, lloraban a los gritos para que cada grupo no se fuera, la situación nos superaba, fue difícil para todos. ¿Se manifestaba allí nuevamente el trauma de la pérdida que tanto habían marcado sus cortas vidas? Al regresar a la actividad cotidiana lo hablamos mucho, como a todo lo que nos pasaba, pero aun hoy nos preguntamos sobre esa experiencia, quizá los años nos dieron la respuesta. En 1994 los mismos chicos, ahora jóvenes, deciden encontrarse en Córdoba, en una reunión de camaradería y encuentros. Allí deciden crear HIJOS. Nunca más se separarían entonces, las circunstancias pueden alejarlos o acercarlos pero algo los identificará para siempre, son hijos de una historia común. Terrible, pero los marcó de una manera determinada, a muchos como luchadores incansables y defensores de la vida.

Voy a tratar de narrar lo que nos compete como psicólogos: qué hacíamos nosotros en esos talleres. Lo que mejor nos sale: escuchar y tratar de juntos encontrar un sentido a eso que nos pasa. Ese era el taller donde se hablaba de lo que los chicos querían, allí lloraban, se enojaban, discutían, razonaban, obviamente esto mismo se manifestaba en cada uno de los otros espacios de trabajo, en los dibujos, en los juegos, en el teatro, por esto nos reuníamos los talleristas y discutíamos lo que observábamos en cada uno y en el grupo como tal. Allí comprobábamos cómo cada niño resolvía su historia con los recursos que tenía previamente, cómo colaboraba o no su entorno, cómo circulaba la palabra en un ámbito global en la cual ésta había estado prohibida, pudimos comprobar las marcas que las mentiras o el ocultamiento había dejado en sus mentes, y cómo al instalar palabras reparadoras comenzaban a restañarse las heridas, a modificarse los vínculos con sus familiares. 
Como he dicho antes, una de nuestras consignas era no hablar de política partidaria de ninguna manera, pero sí romper con el discurso dominante de vergüenza y escarnio contra los presos y los desaparecidos. Esos hombres y mujeres eran luchadores que habían arriesgado o dado sus vidas por un mundo más justo, por tanto eran dignos de respeto y admiración. Esto que se dice en pocas palabras era motivo de largas charlas y discusiones, uno de los objetivos claros era correr a esos niños del lugar de la discriminación y la vergüenza en que los había subsumido la dictadura. Se habían criado en el silencio, hoy había que restituir el derecho a las preguntas, y a la verdad, donde solo existían mentiras era urgente hablar de la verdad, donde el olvido había sido necesario, había que instalar la memoria, donde estaba la soledad ahora debíamos ahuyentarla con amor y abrazos, dentro de lo posible había que restituir los roles parentales perdidos, donde había estado instalado el desamparo había que establecer nexos de protección.

Es posible extraer algunas consideraciones sobre aquella experiencia.

- Circulación de la palabra: los niños habían sido protagonistas y testigos de historias de horror, pero poco habían podido verbalizar sobre ellas. En este nuevo espacio se podía hablar con la seguridad que todos lo iban a comprender, no iba a ser cuestionado, su palabra era un hecho, además compartido por la mayoría.

- Permanencia de los responsables: una de las responsabilidades más fuertes que nos pusimos los talleristas fue el compromiso de la permanencia. Íbamos a trabajar con niños que habían sufrido abandonos, ausencias, muchas veces sus afectos habían desaparecido de sus vidas de un momento a otro sin ninguna razón posible y nosotros debíamos garantizar que íbamos a estar, no íbamos a desaparecer.

- Manifestación del afecto: esto no se podía hacer sin que prevaleciera el amor, era una tarea hecha para reparar pequeños corazones dañados, a quienes además alguno de nosotros vimos crecer y a quienes amábamos profundamente y de hecho el afecto sigue existiendo entre todos nosotros.

- Recuperación de la verdad: esto fue crucial, venían de historias algunas veces inventadas, otras ocultas, era necesario ahora poner palabras y luz donde no había ni preguntas, darles sentido a términos incomprensibles para cualquiera, por ejemplo explicar qué era un desaparecido, y como es que si estaban muertos no había cementerios ni tumbas.

- Continuidad del proyecto: lo comenzamos sin saber cuánto iba a durar, era ponerse a caminar juntos pero no era una escuela por ejemplo que tiene etapas, era parecido a la vida que transcurre y la misma vida nos iría diciendo.

- Seguridad: los niños se sentían seguros, sabían que contaban con nosotros, que éramos sus referentes y de alguna manera los podíamos proteger.

- Referencia histórica y geográfica: Ellos eran el producto de un quehacer histórico y pertenecían a un lugar, el taller "Había una vez" de Rosario, y así se presentaban.

- Aprendizaje: se vivían modalidades de aprendizaje que posiblemente eran innovadoras para ellos, al incorporar métodos creativos.

- Alegría: esto fue un pilar, estábamos felices de compartir ese espacio, de reunirnos chicos y grandes y estar juntos, y lo pasábamos muy bien, ninguno de nosotros estaba obligado o a disgusto allí, éramos felices juntos en verdad y eso se sentía y la alegría es saludable.

¿Qué conclusiones podemos extraer de esta experiencia? 
Nuestra generación fue protagonista de hechos marcadamente fuertes desde lo político y social, viviendo un momento histórico en que la lucha por la liberación del sistema capitalista predominaba en gran parte de América Latina, y donde la lucha armada era no sólo un camino posible sino a veces pensado como el único o por lo menos el más importante. Miembros de una generación que sintió que su deber era comprometerse por una patria liberada y que asumió esa tarea de manera ineludible.

Participantes de una época donde la violencia de un estado arrasaba de manera brutal a todo lo que se opusiese a su designio político económico.

En este período los niños se constituyeron en víctimas privilegiadas. Creo decir con fundamento que nadie creyó o imaginó que ellos podían ser secuestrados, torturados o asesinados, eso no respondía a ningún pensamiento que ingresara en nuestra lógica. No nos habíamos dado cuenta que ninguna lógica tenía que ver con lo que acontecía. Quizá, de haber sabido lo que Franco hizo con los niños republicanos, por ejemplo, hubiéramos previsto algo de lo que sucedió después, pero aquello fue y es aún una historia silenciada, cuyas víctimas siguen padeciendo sus efectos. Aun los niños que permanecieron junto a sus familias vivieron situaciones de extrema tensión. Cómo quedó esa historia registrada en sus psiquis, es materia de estudio aun pendiente.

Según los teóricos de la transmisión generacional, al no poder elaborarse los traumas causados por la violencia política de forma consciente y abierta, ya sea por razones externas (represión o estar luchando contra la represión) o internas (negación y desbordamiento psíquico), sus efectos nocivos interfieren en el funcionamiento social y político de futuras generaciones.

Frente a una situación horrorosa y estigmatizante las secuelas en la psiquis equivalen a un trauma, a él solo es posible hacerle frente con los recursos que la psiquis les brinde pero por sobre todo a una edad tan temprana, los que el entorno les brinde. Dice Clara Valverde Gefaell (2014) "El no nombrar lo que vemos y sentimos no es bueno para la salud de nuestra sociedad", y agrega: "El silencio otorga el horror".

Una de las significaciones más difíciles de explicar fue la de desaparecidos. Cómo poner palabras a aquello que fue creado para el silencio, esa ausencia creada para no dar explicaciones. Hubo que entre todos dar cuerpo a eso que no estaba. Las sociedades han creado ciertos ritos que dan lugar a los pasajes, los ritos en torno a la muerte marcan las diferentes culturas de manera predominante, acompañan el doloroso paso de la pérdida de alguien amado haciendo posible simbolizarlo. Si esto se borra de un golpe, si el padre o la madre de pronto no están más o si nunca los conocieron y hay tan poco de ellos para recordarlos, es necesario realizar una reconstrucción de aquello ausente con los elementos posibles. Una niña nacida en cautiverio cuyo papá es asesinado antes de ella nacer, dice: "lo que más me duele es que mi papá nunca me tocó”. Otro pregunta: "¿él sabía que yo iba a nacer? Otro niño arma con plastilina un cementerio en donde enterrar a su padre desaparecido. La desaparición se basa en la producción de desconocimiento. $\mathrm{Y}$ al desconocimiento se lo combate con la recuperación de la memoria y el conocimiento de la verdad.

Cuando la verdad en torno a aquello que ocurrió es ocultada o falseada, algo de la misma se filtra y el niño crea otra verdad frente a eso que le están ocultando.

Posiblemente uno de los logros fundamentales del proceso colectivo de inclusión de estos niños en el taller fue el de que ellos pudieran comenzar a inscribir sus historias individuales en 
un marco social, tal como Halbwachs (2004) plantea en "Los marcos sociales de la memoria" acerca de la importancia de la relación entre los constructores sociales y la memoria individual. Lo que les había sucedido a cada uno de ellos -y que hasta ahora en la mayoría de los casos había sufrido y procesado como pudieron, generalmente en silencio- en esta experiencia grupal se hacía posible incluirlo en la historia colectiva, en la historia del país, formaban parte de un proceso social.

En definitiva la realidad nos marcaba a cada paso pero -a diferencia de lo que los niños habían vivido anteriormente- ahora en lugar de silencio circulaban palabras. Donde había habido soledad ahora estaba el abrazo de los compañeros y los talleristas, y en el lugar del ocultamiento ahora se hacía presente la verdad.

Y este es el valor del taller Había una vez, del taller Julio Cortazar, del de la Amistad: haber podido accionar activamente frente al trauma, permitir a los niños y a nosotros mismos dejar de ser víctimas pasivas ante el horror social vivido y transformarnos en sujetos activos protagonistas de una experiencia reparadora de lo traumático vivido. Posicionarnos de otra manera frente a lo porvenir.

Hoy, aquellos niños son maestros, artistas, empresarios, operadores sociales, cineastas, titiriteros, de lo que busquemos encontraremos entre ellos, viven en distintos lugares del mundo, pero tienen un entrañable recuerdo por el querido taller que los ayudó a crecer y a vivir en los momentos más difíciles de sus cortas vidas.

\section{Referencias Bibliográficas}

- Halbwachs, M. (2004) [1925]: Los marcos sociales de la memoria, Barcelona: Anthropos Editorial.

- Valverde Gefaell, C (2014) Desenterrar las plabras. Transmisión generacional del trauma de la violencia política del siglo XX en el estado español. España: Ivaria Editorial. 